\title{
Suspending Loads Decreases Load Stability but May Improve Locomotion Stability
}

\author{
Jeffrey Ackerman, $\mathrm{PhD}^{\mathrm{a}}$, Karna Potwar ${ }^{\mathrm{a}}$, Justin Seipel, $\mathrm{PhD}^{\mathrm{a} *}$
}

Key Words: Stability, Running, Locomotion, Load carriage, Backpack suspension, Vibration isolation

a Full Length Article for the Journal of Biomechanics

1 December 2016

\footnotetext{
${ }^{a}$ School of Mechanical Engineering, Purdue University, West Lafayette, IN 47907

* to whom all correspondence should be addressed

585 Purdue Mall

West Lafayette, IN 47907-2088

jseipel@purdue.edu

phone: (765) 494-3376
}

(C) 2016. This manuscript version is made available under the Elsevier user license 


\begin{abstract}
Here, we seek to determine how compliantly suspended loads could affect the dynamic stability of legged locomotion. We theoretically model the dynamic stability of a human carrying a load using a coupled spring-mass-damper model and an actuated spring-loaded inverted pendulum model, as these models have demonstrated the ability to correctly predict other aspects of locomotion with a load in prior work, such as body forces and energetic cost. We report that minimizing the load suspension natural frequency and damping ratio reduces the stability of the load mass but improves the whole-body stability of locomotion when compared to a rigidly attached load. These results imply that a highly-compliant load suspension could help stabilize legged locomotion during human, animal, or robot load carriage, but at the cost of a more awkward (less stable) load.
\end{abstract}




\section{Introduction}

Humans, animals, and robots can benefit from compliantly suspending loads from their bodies, but little is known about how the stability of locomotion may be impacted in the process. The first documented use of a highly-compliant load suspension are humans carrying heavy loads with compliant bamboo carrying poles, which were initially adopted in Southeast Asia (Castillo et al., 2014; Kram, 1991; Potwar et al., 2014) (Figure 1a). More recently, various highly-compliant suspension systems have been developed to assist humans carrying heavy camera systems using the Steadicam ${ }^{\circledR}$ stabilizing arm (Ackerman and Seipel, 2015; Jurgens, 1978) (Figure 1b), backpack loads (Foissac et al., 2009; Rome et al., 2006, 2005) (Figure 1c), and hand-held loads (Ackerman et al., 2015). Highly-compliant load suspensions are also useful to improve the locomotion efficiency of horses (de Cocq et al., 2013; Pfau et al., 2009) (Figure 1d) and legged robots (Ackerman et al., 2012a, 2012b, Ackerman and Seipel, 2013, 2011a; Xingye et al., 2013) (Figure 1e). Recent work shows that the effective stiffness and damping of the load suspension should be minimized to reduce the peak forces acting on the body (Hoover and Meguid, 2011; Kram, 1991; Ren et al., 2005; Xingye et al., 2013) and the energetic cost of locomotion (Ackerman and Seipel, 2014, 2013; de Cocq et al., 2013; Foissac et al., 2009; Rome et al., 2006; Xingye et al., 2013).

Though there are many established benefits of load carriage with a compliant suspension, there is little published work that investigate how the stability of locomotion is impacted by an elastically suspended load. It is important to consider the effect of load suspensions on the stability of locomotion because stability can affect one's ability to carry heavy loads rapidly in complex environments, how it "feels" for a human to carry a load, and the control of legged robots.

Our objective in this paper is to develop theoretical understanding of how a highlycompliant load suspension could affect the dynamic stability of running, which is defined here as the decay of perturbations to the center-of-mass position and velocity over one cycle (Full et al., 2002). We chose to focus on human running because prior work shows that a highly-compliant load suspension is most useful at higher stepping frequencies (Ackerman and Seipel, 2014; Hoover and Meguid, 2011; Kram, 1991; Rome et al., 2006). Stability is critically important during running due to the high dynamic speeds and forces involved. Further, running with heavy 
loads is of a particular concern in the US military, where estimated soldier loads can be over 35 $\mathrm{kg}$ (Knapik et al., 2004).

We hypothesize that:

1. The stability of a carried load during running will be decreased when the load is coupled to the main body via a highly-compliant suspension compared to running with a rigidly attached load of equal mass. This hypothesis is based on basic linear system theory, which shows that a highly-compliant and lightly-damped load mass will have a lower natural frequency and longer settling time than if it were stiffly/rigidly attached, so perturbations to the position and velocity of the suspended load will take longer to decay back to steady state.

2. The stability of the main body mass will be increased (perhaps counter-to-intuition) when the load is coupled to the main body via a highly-compliant suspension compared to running with a rigidly attached load of equal mass. This hypothesis is informed by the authors' earlier theoretical studies on this subject and prior experimental results. Preliminary analysis by the authors on a coupled-mass vertical hopper model (Ackerman and Seipel, 2012) demonstrated that the stability of the main body mass could be improved with a compliant suspension. Prior experimental work showed that a horse rider with a 'compliant' leg posture reduced the variability in the horse's velocity compared to the horse trotting by itself (Peham et al., 2004). Further, the authors' previously conducted preliminary experimental work with a legged robot carrying a suspended load over rough terrain which showed that the robot traveled over the terrain at a faster speed while experiencing fewer failures compared to carrying a rigidly attached load (Ackerman et al., 2012b), suggesting that the suspended load may have increased the robot's locomotion stability.

Our overall approach is to test our hypotheses using two well-established theoretical modeling frameworks for locomotion with different fidelity to check for a consensus of corroborating results and establish a theoretical framework that may also enable the design of future experiments. The established models we use here are i) a coupled body-load spring-massdamper model of vertical motion (Coupled SMD model) (Figure 2a) and ii) an actuated SpringLoaded Inverted Pendulum with a vertically-constrained suspended load mass model (SLIP-Load model) (Figure 2b). These models have been used effectively to answer other questions about human locomotion (Abraham et al., 2015; Ackerman and Seipel, 2016, 2014, 2013, 2012, 2011b, Potwar et al., 2014, 2013, Shen and Seipel, 2012, 2015a, 2015b; Xingye et al., 2013). 


\section{Methods}

\section{Coupled SMD Model}

First, we analyze the linear two degree of freedom Coupled SMD model to determine how a load suspension affects the stability of the coupled load and body mass in the vertical direction (Figure 2a). This model has been used extensively in the study of coupled-oscillators (Den Hartog, 2007) and the vibration of a quarter-car suspension (Sharp and Crolla, 1987). The author's previously used this model to study how the forces and energetics of human and robot walking are affected by a suspended load (Ackerman and Seipel, 2014, 2013, 2012, 2011b; Xingye et al., 2013).

The Coupled SMD model is forced using a sinusoidal base excitation and represents the vertical dynamics of a human walking or running with a load (Ackerman and Seipel, 2014). The equations of motion for the Coupled SMD model forced with a base excitation $\mathrm{L}(\mathrm{t})$ with respect to static equilibrium are:

$$
\begin{gathered}
M \ddot{Y}+c(\dot{\mathrm{Y}}-\dot{\mathrm{y}})+k(y-Y)+\mathrm{C}(\dot{\mathrm{Y}}-\dot{\mathrm{L}})+\mathrm{K}(Y-L)=0, \\
m \ddot{y}+c(\dot{y}-\dot{Y})+k(y-Y)=0 . \\
L(t)=\mathrm{a} * \sin (\omega \mathrm{t}), \dot{L}(t)=\mathrm{a} \omega * \cos (\omega \mathrm{t}),
\end{gathered}
$$

We used representative parameters to simulate human running (Table 1).

The stability of this model is calculated by perturbing the initial conditions of the system $\left(\partial Y_{0}, \partial \dot{Y}_{0}, \partial y_{0}, \partial \dot{y}_{0}\right)$ with a magnitude of 0.01 , estimating the partial derivatives using finite differences for the mapping from one period to the next, and calculating the eigenvalues of the resulting linearized Jacobian matrix. This method can quantify the relative growth or decay of perturbations to the state variables in a coupled system (Full et al., 2002). For the Coupled SMD model, the Jacobian is

$$
J=\left[\begin{array}{llll}
\frac{\partial Y}{\partial Y_{0}} & \frac{\partial Y}{\partial \dot{Y}_{0}} & \frac{\partial Y}{\partial y_{0}} & \frac{\partial Y}{\partial \dot{y}_{0}} \\
\frac{\partial \dot{Y}}{\partial Y_{0}} & \frac{\partial \dot{Y}}{\partial \dot{Y}_{0}} & \frac{\partial \dot{Y}}{\partial y_{0}} & \frac{\partial \dot{Y}}{\partial \dot{y}_{0}} \\
\frac{\partial y}{\partial Y_{0}} & \frac{\partial y}{\partial \dot{Y}_{0}} & \frac{\partial y}{\partial y_{0}} & \frac{\partial y}{\partial \dot{y}_{0}} \\
\frac{\partial \dot{y}}{\partial Y_{0}} & \frac{\partial \dot{y}}{\partial \dot{Y}_{0}} & \frac{\partial \dot{y}}{\partial y_{0}} & \frac{\partial \dot{y}}{\partial \dot{y}_{0}}
\end{array}\right] .
$$


The eigenvectors associated with the eigenvalues of the linearized Jacobian matrix show the relative correspondence between the eigenvalues and the state variables in a coupled system (Table 2).

Once perturbed, this system will return to a limit cycle with period T:

$$
T=\frac{2 \pi}{\omega} \text {. }
$$

Here we study the three variables associated with the suspended load: the load mass

magnitude $\mathbf{M}$, the load suspension natural frequency $\omega_{n}$, and the damping ratio $\zeta$. The damping ratio is a dimensionless measure of damping which changes the effective stiffness and damped natural frequency of the system. The effective stiffness $K$ of the load suspension can be defined by the natural frequency, damping ratio, and load mass,

$$
K=M\left(\frac{\omega_{n}}{\sqrt{1-\zeta^{2}}}\right)^{2}
$$

The load suspension damping coefficient $\mathrm{C}$ can be defined by the damping ratio, effective stiffness, and load mass,

$$
C=2 \zeta \sqrt{K M}
$$

\section{SLIP-Load Model}

Second, we analyze the stability of the nonlinear SLIP-Load model (Potwar et al., 2014) (Figure 2b). This model provides a more realistic representation of the coupled fore-aft and vertical whole-body sagittal-plane dynamics of a human running with a load.

The hip-actuated SLIP model (Shen and Seipel, 2012) is a highly-stable model which can describe the center-of-mass dynamics of human and animal running using realistic parameters. Unlike the traditional energy-conserving SLIP model (Blickhan, 1989; Blickhan and Full, 1993), the hip-actuated SLIP model inputs energy into the system by applying torque to the virtual leg about the hip and removes energy from the system through a damper acting along the virtual leg. Prior versions of this model have been used to study the effects of the virtual leg torque, stiffness, and damping on the energetic cost, stability, and peak forces of running (Abraham et al., 2015; Ackerman and Seipel, 2016; Shen and Seipel, 2015a, 2015b, 2012). 
We modified this model by attaching a load mass to the body mass with a verticallyconstrained suspension (Figure 2b). The parameters of the SLIP-Load model were selected to approximate a human running with a load (Table 1).

The equations of motion of the SLIP-Load model were derived via Newton's method. As in prior work, the virtual leg, or spring-leg, is defined as the distance between the body center of mass and the foot center of pressure (Andrada et al., 2014; Blickhan, 1989; Blickhan and Full, 1993; Daley et al., 2007; Farley et al., 1993; McMahon and Cheng, 1990; Shen and Seipel, 2012). The angle $\theta$ of the virtual leg during the stance phase with respect to the horizontal axis is

$$
\theta=\tan ^{-1}\left(\frac{\mathrm{x}-\mathrm{x}_{\mathrm{f}}}{\mathrm{y}}\right)+\frac{\pi}{2} .
$$

The position $\mathrm{x}_{\mathrm{f}}$ is the foot center of pressure at the distal end of the virtual leg in contact with the ground during the stance phase. The position of the body center-of-mass is described by the coordinates $x$ and $y$. The length of the virtual leg during the stance phase is

$$
\mathrm{l}=\sqrt{\left(\left(x-x_{\mathrm{f}}\right)^{2}+y^{2}\right)} .
$$

The force along the virtual leg, the force perpendicular to the virtual leg, and the suspension force acting on the body are

$$
\begin{gathered}
\mathrm{F}_{\mathrm{L}}=\mathrm{k}\left(\mathrm{l}_{\mathrm{o}}-\mathrm{l}\right)-\frac{\mathrm{c}}{\mathrm{l}}((\mathrm{x}-\mathrm{f}) \dot{\mathrm{x}}+\mathrm{y} \dot{\mathrm{y}}), \\
\mathrm{F}_{\mathrm{T}}=\frac{\tau}{\mathrm{l}} \\
\mathrm{F}_{\mathrm{S}}=\mathrm{K}(\mathrm{Y}-\mathrm{y})+\mathrm{C}(\dot{\mathrm{Y}}-\dot{\mathrm{y}}) .
\end{gathered}
$$

We assume a constant virtual leg torque as done in prior work with Actuated SLIP-based models (Abraham et al., 2015; Ackerman and Seipel, 2016; Potwar et al., 2014; Shen and Seipel, 2015a, 2015b, 2012). Though this is not an accurate representation of the torque profile in an actual human leg, prior work has shown that this modeling framework is capable of making good stability, energetic, and force predictions for legged locomotion in general, including human locomotion.

During running, the model has a distinct stance phase where the virtual leg is in contact with the ground and a flight phase where the virtual leg leaves the ground and the body undergoes projectile motion. The equations of motion during the stance phase of running with one virtual leg in contact with the ground are

$$
\ddot{\mathrm{x}}=\frac{\mathrm{F}_{\mathrm{T}} \sin \theta-\mathrm{F}_{\mathrm{L}} \cos \theta}{\mathrm{m}},
$$




$$
\begin{gathered}
\ddot{y}=\frac{F_{L} \sin \theta+F_{T} \cos \theta+F_{S}}{m}-g, \\
\ddot{Y}=-\frac{F_{S}}{M}-g .
\end{gathered}
$$

The model starts in the stance phase when the virtual leg just touches the ground at a given touchdown angle $\theta=\beta$, which occurs when

$$
\mathrm{y}=\mathrm{l}_{\mathrm{o}} \sin \beta .
$$

The initial conditions of the body mass starting from a touchdown event are $\mathrm{v}_{\mathrm{x} 0}$ and $\mathrm{v}_{\mathrm{y} 0}$, which are calculated from the body mass touchdown velocity vector magnitude $v_{0}$ and angle $\delta_{0}$,

$$
\begin{gathered}
\mathrm{v}_{\mathrm{x} 0}=v_{\mathrm{o}} \cos \partial_{0}, \\
\mathrm{v}_{\mathrm{y} 0}=-v_{\mathrm{o}} \sin \partial_{0} .
\end{gathered}
$$

The initial conditions for the load mass starting from a touchdown event are the position $Y_{0}$ and velocity $\dot{Y}_{0}$.

The torque $\tau$ rotates the virtual leg while it is compressed during the stance phase, storing energy in the virtual leg in preparation for lifting off the ground and entering the flight phase. When the vertical forces in the spring and damper along the virtual leg become zero, the system achieves the lift off condition

$$
\mathrm{F}_{\mathrm{L}} \sin \theta+\mathrm{F}_{\mathrm{T}} \cos \theta=0 .
$$

The equations of motion during the flight phase are

$$
\begin{gathered}
\ddot{x}=0 . \\
\ddot{y}=\frac{F_{S}}{m}-g, \\
\ddot{Y}=-\frac{F_{S}}{M}-g .
\end{gathered}
$$

The model transitions back to the stance phase when the next virtual leg touches the ground again at the touchdown angle $\theta=\beta$.

A version of this model was introduced previously (Potwar et al., 2013), but this version was found to significantly change speed as the load suspension stiffness varied. Later, a continuous torque-based speed controller was added to maintain a specified running speed, and this model was found to predict the dynamic behavior of the human body while running with a highly-compliant pole suspension and a rigid load (Potwar et al., 2014). Here, we take a similar approach by discretely adjusting the constant virtual leg torque $\tau$ from stride-to-stride using a 
numerical solver to achieve a specified average running speed. Controlling the average speed is important to make fair comparisons between the model results when the suspension parameters are varied and is akin to comparing a human running on a treadmill at a constant speed with different load configurations.

The virtual leg damping removes energy from the system, so prescribing the virtual leg damping value requires the torque to be adjusted as described to add the appropriate amount of energy to the system. There are few prior experimental studies on the effective damping of the human leg, but one prior experiment estimates that the effective human leg damping during vertical body oscillation is $950 \mathrm{Ns} / \mathrm{m}$ (Zhang et al., 2000). For the SLIP-Load model, we estimated the virtual leg damping to be a constant $1200 \mathrm{Ns} / \mathrm{m}$ to maintain stability with large load mass variations (Table 1).

The virtual leg stiffness is derived from an established dimensionless leg stiffness ratio (Ackerman and Seipel, 2016; Blickhan and Full, 1993; Shen and Seipel, 2015a, 2015b, 2012). Here we assume that the dimensionless virtual leg stiffness ratio is affected by the combined body and load mass (Table 1), which is based on recent work showing that the effective human leg stiffness increases almost linearly with added body mass (Silder et al., 2015).

The same methodology outlined previously can be used to analyze the stability of this model. First, the initial conditions and the virtual leg torque are adjusted from touchdown to touchdown until a steady state limit cycle is achieved with an error less than 1E-9. Then, the initial conditions of the system $\left(\partial \mathrm{v}_{\mathrm{x} 0}, \partial \mathrm{v}_{\mathrm{y} 0}, \partial Y_{0}, \partial \dot{Y}_{0}\right)$ are perturbed with a magnitude of 0.01 , the partial derivatives $\left(\partial \mathrm{v}_{\mathrm{x}}, \partial \mathrm{v}_{\mathrm{y}}, \partial Y, \partial \dot{Y}\right)$ are estimated using finite differences for the mapping from one touchdown to the next, and the eigenvalues of the resulting linearized Jacobian matrix are calculated. For the SLIP-Load model, the Jacobian is

$$
J=\left[\begin{array}{llll}
\frac{\partial \mathrm{v}_{\mathrm{x}}}{\partial \mathrm{v}_{\mathrm{x} 0}} & \frac{\partial \mathrm{v}_{\mathrm{x}}}{\partial \mathrm{v}_{\mathrm{y} 0}} & \frac{\partial \mathrm{v}_{\mathrm{x}}}{\partial Y_{0}} & \frac{\partial \mathrm{v}_{\mathrm{x}}}{\partial \dot{Y}_{0}} \\
\frac{\partial \mathrm{v}_{\mathrm{y}}}{\partial \mathrm{v}_{\mathrm{x} 0}} & \frac{\partial \mathrm{v}_{\mathrm{y}}}{\partial \mathrm{v}_{\mathrm{y} 0}} & \frac{\partial \mathrm{v}_{\mathrm{y}}}{\partial Y_{0}} & \frac{\partial \mathrm{v}_{\mathrm{y}}}{\partial \dot{Y}_{0}} \\
\frac{\partial Y}{\partial \mathrm{v}_{\mathrm{x} 0}} & \frac{\partial Y}{\partial \mathrm{v}_{\mathrm{y} 0}} & \frac{\partial Y}{\partial Y_{0}} & \frac{\partial Y}{\partial \dot{Y}_{0}} \\
\frac{\partial \dot{Y}}{\partial \mathrm{v}_{\mathrm{x} 0}} & \frac{\partial \dot{Y}}{\partial \mathrm{v}_{\mathrm{y} 0}} & \frac{\partial \dot{Y}}{\partial Y_{0}} & \frac{\partial \dot{Y}}{\partial \dot{Y}_{0}}
\end{array}\right] .
$$




\section{Results}

\section{Coupled SMD Model}

The Coupled SMD model (Figure 2a) shows that the stability of a load suspended with a highly-compliant and lightly-damped suspension (solid black topmost line) is significantly decreased compared to a rigidly attached load (dotted black bottommost line) (Figure 3a). These eigenvalue branches primarily correspond with the load state variables, which can be observed in the associated eigenvectors (Table 2). The other two eigenvalue branches primarily correspond to the body mass degrees of freedom (Table 2) and show that the stability of the body mass increases with a highly-compliant and lightly-damped load suspension relative to a rigidly attached load as the load mass increases (Figure 3a).

The rigidly attached load case shows mixed eigenvectors corresponding to the body mass degrees of freedom (Table 2) because the load mass is tightly coupled to the body mass (Figure 4). The highly compliant and lightly damped load suspension decouples the motion of the load mass from that of the body mass (Figure 4), reducing the interaction between the load and body mass degrees of freedom in the eigenvectors (Table 2).

If the natural frequency (Figure 3c) or damping ratio (Figure 3e) of the load suspension increases, the stability of a suspended load (solid black line) improves but is still significantly less stable than a rigidly attached load (dotted black bottommost line). The relative stability improvement corresponding to the body mass degrees of freedom remains approximately the same with a suspended load compared to a rigidly attached load over a range of natural frequencies from 0.1-1.5 Hz (Figure 3c) and damping ratios between 0.1-0.5 (Figure 3e), showing that the result is robust over a typical load suspension parameter range.

To visually observe the eigenvalue results, the time response of all state variables to perturbations in each state variable are shown in Figure 5. These perturbation responses confirm that the body mass degrees of freedom return to steady state faster with a suspended load compared to a rigidly attached load. The load mass degrees of freedom take significantly longer to return to steady state with a suspended load versus a rigidly attached load. 


\section{SLIP-Load Model}

The SLIP-Load model (Figure 3b) also shows that the stability of a load suspended with a highly-compliant and lightly-damped suspension (solid black topmost line) is significantly decreased compared to a rigidly attached load (dotted black bottommost line) (Figure 3b). These eigenvalue branches closely correlate with the load state variables, which can be seen in the eigenvectors (Table 2).

The other eigenvalue branches (blue and red lines) primarily correspond to the body mass degrees of freedom, though there is significant mixing between the body mass and the load mass degrees of freedom with the rigidly attached load because the load mass is tightly coupled to the body mass (Figure 4) (Table 2). The blue eigenvalue branches show that the stability of the body mass increases with a highly-compliant and lightly-damped load suspension relative to a rigidly attached load as the load mass increases, and the more stable red eigenvalue branches do not show a significant difference between a suspended load and a rigid load (Figure $3 b$ ).

If the natural frequency (Figure 3d) or damping ratio (Figure 3f) of the load suspension increases, the stability of a suspended load (solid black line) improves, but the load is still significantly less stable than a rigidly attached load (dotted black bottommost line). The blue eigenvalue branches corresponding to the body mass degrees of freedom with the suspended load show a further stability improvement relative to the rigidly attachment load with increasing load suspension natural frequencies from 0.1-1.5 Hz (Figure 3d) and damping ratios from 0.1-0.5 (Figure 3f), but the red eigenvalues branches still do not show significant differences between the suspended and rigidly attachment loads. These trends indicate that the stability result is robust over a typical load suspension parameter range for the nonlinear SLIP-Load model.

The time response of all state variables to perturbations in each state variable are shown in Figure 6. These dynamic perturbation responses agree with the overall results of the stability analysis, showing that the body mass degrees of freedom generally return to steady state faster with a suspended load compared to a rigidly attached load. The suspended load mass degrees of freedom take much longer to return to steady state compared to the rigidly attached load, showing that the suspended load is less stable than the rigid load.

We also tried different torque models (see supplement) which show that the overall conclusions from the SLIP-Load model are relatively insensitive to the chosen torque model. 


\section{Discussion}

\section{Reduced Suspended Load Mass Stability}

Both models show that the suspended load is significantly less stable than the rigidly attached load (Figure 3), confirming the first hypothesis.

If the stability of the load mass is reduced with a highly-compliant suspension, the load carrier may perceive that they have less control over the motion of the load and that the load feels more awkward to carry compared to a stiffly/rigidly attached load. The authors' have experienced this feeling themselves and heard comments about an awkward feeling from participants during an experiment testing a hand-held load suspension (Ackerman et al., 2015). In another experimental study, participants carrying a load with a compliant bamboo pole reported that "balancing the pole was difficult and uncomfortable" (Castillo et al., 2014). The awkward feeling noted by the subjects in these studies could have been caused by asymmetric loading, insufficient habituation, or the challenge of balancing a long pole on their shoulder (Potwar et al., 2014), but we expect that part of this awkward feeling is a result of the reduced stability of a compliant load. The reduction in the stability of the load mass may be particularly noticeable when the user initiates locomotion from rest, the user comes to a stop, or the load physically interacts with the environment. Under these circumstances, the load will be perturbed from its equilibrium position or limit cycle, and it will take longer for the load to return to steady state without active input from the user.

This potentially awkward feeling could be improved by increasing the natural frequency or the damping ratio of the suspension to reduce oscillations and damp perturbations more quickly (Figure 3c-f). However, increasing the suspension stiffness and damping to increase the stability of the load mass represents a design tradeoff because the peak force reduction (Ackerman and Seipel, 2011b; Foissac et al., 2009; Hoover and Meguid, 2011; Kram, 1991; Rome et al., 2006, 2005) and potential energetic benefits (Ackerman and Seipel, 2014, 2013, 2011a, Rome et al., 2006, 2005; Xingye et al., 2013) offered by a load suspension could be compromised if the suspension stiffness or damping is too high.

Training and experience may be helpful for a user to become acclimated to carrying a suspended load. For example, Steadicam ${ }^{\circledR}$ operators carry heavy camera rigs with a lightlydamped and highly-compliant stabilizing arm suspension for hours at a time after sufficient 
training and experience (Jurgens, 1978). Steadicam ${ }^{\circledR}$ operators likely adapt their gait in response to or to compensate for the less stable load suspension. They also have some direct control over the load motion by manipulating a control arm attached to the camera sled gimbal, which could help to actively damp perturbations or to give the user a feeling of control through tactile feedback. Users of bamboo carrying poles also appear to hold the suspended load or pole to help stabilize the load (Balogun, 1986; Castillo et al., 2014; Datta and Ramanathan, 1971; Kenntner, 1969; Kram, 1991; Potwar et al., 2014).

Horse jockeys are another example of a highly-compliant load suspension because they actively suspended their body from a galloping horse via a 'compliant' leg posture (de Cocq et al., 2013). While racing, a jockey is working near their maximal heart rate to actively maintain their 'compliant' leg posture (Pfau et al., 2009), which may be caused in part by increased muscular effort to stabilize their own motion.

\section{Increased Body Mass Stability}

Both models show that the stability of the body mass is increased with a suspended load mass (Figure 3), confirming the second hypothesis. The differences in the stability of the body mass appear to be caused by the coupled dynamic interactions between the body and load mass. The motion of the highly-compliant and lightly-damped load suspension is decoupled from that of the body mass (Figure 4), which reduces the dynamic interaction between the load mass and the body mass (Table 2). With a stiffly/rigidly attached load, the load mass is tightly coupled to the body mass such that perturbations to the load mass can significantly affect the motion of the body mass, which may increase the magnitude of the eigenvalues corresponding to the body mass state variables as the load mass magnitude increases (Figure 3a-b).

Prior work shows that an experienced rider utilizing a compliant leg posture (de Cocq et al., 2013) reduces the variability in the horizontal and vertical velocity of their horse compared to the horse alone (Peham et al., 2004). While this phenomenon may be largely explained by the communication between a skilled rider and their horse, the SLIP-Load model shows that the eigenvalues corresponding to the $\mathrm{v}_{\mathrm{x}}$ and $\mathrm{v}_{\mathrm{y}}$ state variables are reduced with a highly-compliant load when compared with a rigidly attached load or with no load and may provide a partial explanation for this experimental result. 
Similarly, highly-compliant load suspensions may be useful to help stabilize the motion of legged robots, which currently struggle to stabilize themselves during locomotion. A highlycompliant load suspension that supports external loads or a portion of the inherent robot mass could improve the stability of the robot while reducing the energetic cost of locomotion (Ackerman et al., 2012a, 2012b, Ackerman and Seipel, 2013, 2011a; Xingye et al., 2013). This effect may be particularly helpful over challenging rugged terrain because less active control effort may be required to compensate for environmental perturbations. The authors' prior experimental work with a legged robot carrying a suspended load over a rough terrain obstacle course showed that the robot traveled over the terrain more quickly while consuming less power and experiencing fewer failures compared to carrying a rigidly attached load (Ackerman et al., 2012b), suggesting that the suspended load may have increased the robot's locomotion stability compared to a rigid load.

Limited experimental evidence exists regarding the stability of the body during locomotion with a load suspension, and future experimental perturbation studies are needed to validate whether the stability of the body is improved with a suspended load compared to a rigidly attached load. However, both the well-established linear Coupled SMD and nonlinear SLIP-Load model of locomotion with a load yield similar corroborating results and appear to explain the available evidence, which results in a strong theoretical hypothesis that could be tested in future experimental work.

\section{Acknowledgements}

This research was conducted with government support under and awarded by NSF CMMI-1131423, DoD, Air Force Office of Scientific Research, National Defense Science and Engineering Graduate (NDSEG) Fellowship, 32 CFR 168a. The authors would like to thank Dr.

Shirley Rietdyk, Dr. Eric Nauman, Dr. Zhuohua Shen, and Manish Anand for their help and advice.

Approximate word count for Introduction through Acknowledgments: 4069. 


\section{Conflict of interest statement}

The authors have founded a company for the development of hand-held carrying devices. The terms of this arrangement have been reviewed by Purdue University in accordance with its conflict of interest policies and any real or apparent $\mathrm{CoI}$ is managed.

\section{References}

Abraham, I., Shen, Z., Seipel, J., 2015. A Nonlinear Leg Damping Model for the Prediction of Running Forces and Stability. J. Comput. Nonlinear Dyn. 10, 51008. doi:10.1115/1.4028751

Ackerman, J., Kelley, K., Seipel, J., 2015. Dynamics of carrying a load with a handle suspension. J. Biomech. doi:10.1016/j.jbiomech.2015.01.025

Ackerman, J., Seipel, J., 2016. Effects of independently altering body weight and mass on the energetic cost of a human running model. J. Biomech. 49, 691-697. doi:10.1016/j.jbiomech.2016.01.016

Ackerman, J., Seipel, J., 2015. Design of Stabilizing Arm Mechanisms for Carrying and Positioning Loads. ASME J. Mech. Des. 137, 104501. doi:10.1115/1.4030987

Ackerman, J., Seipel, J., 2014. A Model of Human Walking Energetics with an ElasticallySuspended Load. J. Biomech. 47, 1922-1927. doi:http://dx.doi.org/10.1016/j.jbiomech.2014.03.016

Ackerman, J., Seipel, J., 2013. Energy Efficiency of Legged Robot Locomotion with Elastically Suspended Loads. IEEE Trans. Robot. 29, 321-330. doi:10.1109/tro.2012.2235698

Ackerman, J., Seipel, J., 2012. Energy Efficiency and Stability of a Nonlinear CoupledOscillator Model of Hopping with Elastically-Suspended Loads. ASME Int. Des. Eng. Tech. Conf.

Ackerman, J., Seipel, J., 2011a. Energetics of Bio-Inspired Legged Robot Locomotion with Elastically-Suspended Loads. IEEE/RSJ Int. Conf. Intell. Robot. Syst.

Ackerman, J., Seipel, J., 2011b. Coupled-Oscillator Model of Locomotion Stability with Elastically-Suspended Loads. ASME Int. Des. Eng. Tech. Conf.

Ackerman, J., Xingye, D., Seipel, J., 2012a. Energy Efficiency of Legged Robot Locomotion with Elastically-Suspended Loads Over a Range of Suspension Stiffnesses. ASME Int. Des. Eng. Tech. Conf.

Ackerman, J., Xingye, D., Seipel, J., 2012b. Mobility of Legged Robot Locomotion with Elastically-Suspended Loads Over Rough Terrain. 15th Int. Conf. Climbing Walk. Robot.

Andrada, E., Rode, C., Sutedja, Y., Nyakatura, J.A., Blickhan, R., 2014. Trunk orientation causes asymmetries in leg function in small bird terrestrial locomotion. Proceedings. Biol. Sci. 281. doi:10.1098/rspb.2014.1405

Balogun, J.A., 1986. Ergonomic comparison of three modes of load carriage. Int. Arch. Occup. 
Environ. Health 58, 35-46.

Blickhan, R., 1989. The Spring-Mass Model for Running and Hopping. J. Biomech. 22, $1217-$ 1227.

Blickhan, R., Full, R.J., 1993. Similarity in Multi-Legged Locomotion: Bouncing Like a Monopode. J. Comp. Physiol. A Neuroethol. Sensory, Neural, Behav. Physiol. 173, 509517.

Castillo, E., Lieberman, G., McCarty, L., Lieberman, D., 2014. Effects of pole compliance and step frequency on the biomechanics and economy of pole carrying during human walking. J. Appl. Physiol. 117, 507-17. doi:10.1152/japplphysiol.00119.2014

Daley, M.A., Felix, G., Biewener, A.A., 2007. Running stability is enhanced by a proximo-distal gradient in joint neuromechanical control. J. Exp. Biol. 210, 383-394.

doi: $10.1242 /$ jeb. 02668

Datta, S.R., Ramanathan, N.L., 1971. Ergonomic comparison of seven modes of carrying loads on the horizontal plane. Ergonomics 14, 269-278.

de Cocq, P., Muller, M., Clayton, H.M., van Leeuwen, J.L., 2013. Modelling biomechanical requirements of a rider for different horse-riding techniques at trot. J. Exp. Biol. 216, 185061. doi:10.1242/jeb.070938

Den Hartog, J.P., 2007. Mechanical vibrations, 4th ed. Dover Publications, Mineola.

Epstein, Y., Stroschein, L.A., Pandolf, K.B., 1987. Predicting metabolic cost of running with and without backpack loads. Eur. J. Appl. Physiol. Occup. Physiol. 56, 495-500.

Farley, C.T., Glasheen, J., McMahon, T.A., 1993. Running springs: speed and animal size. J. Exp. Biol. 185.

Foissac, M., Millet, G.Y., Geyssant, A., Freychat, P., Belli, A., 2009. Characterization of the mechanical properties of backpacks and their influence on the energetics of walking. J. Biomech. 42, 125-130.

Full, R.J., Kubow, T., Schmitt, J., Holmes, P., Koditschek, D., Robert, J., Kubow, T., Schmitt, J., Holmes, P., Koditschek, D., 2002. Quantifying Dynamic Stability and Maneuverability in Legged Locomotion. Integr. Comp. Biol. 42, 149.

Geyer, H., Seyfarth, A., Blickhan, R., 2006. Compliant leg behaviour explains basic dynamics of walking and running. Proc. R. Soc. B 273, 2861.

Hoover, J., Meguid, S., 2011. Performance assessment of the suspended-load backpack. Int. J. Mech. Mater. Des. 7, 111-121. doi:10.1007/s10999-011-9153-7

Jurgens, J., 1978. Steadicam as a Design Problem. SMPTE Motion Imaging J. 87, 587-591. doi:10.5594/J10501

Kenntner, G., 1969. Customs and efficiency in carrying loads of the inhabitants of the southern Himalayas. A contribution to biogeographic research. Z. Morphol. Anthropol. 61, 125.

Knapik, J.J., Reynolds, K.L., Harman, E., 2004. Soldier load carriage: historical, physiological, biomechanical, and medical aspects. Mil. Med. 169, 45-56.

Kram, R., 1991. Carrying loads with springy poles. J. Appl. Physiol. 71, 1119-1122.

McMahon, T.A., Cheng, G.C., 1990. The mechanics of running: How does stiffness couple with 
speed? J. Biomech. 23, 65-78. doi:10.1016/0021-9290(90)90042-2

Peham, C., Licka, T., Schobesberger, H., Meschan, E., 2004. Influence of the rider on the variability of the equine gait. Hum. Mov. Sci. 23, 663-71.

doi:10.1016/j.humov.2004.10.006

Pfau, T., Spence, A., Starke, S., Ferrari, M., Wilson, A., 2009. Modern riding style improves horse racing times. Science (80-. ). 325, 289.

Potwar, K., Ackerman, J., Seipel, J., 2014. Design of Compliant Bamboo Poles for Carrying Loads. J. Mech. Des. 137, 11404. doi:10.1115/1.4028757

Potwar, K., Ackerman, J., Seipel, J., 2013. SLIP Model of Human Running with an ElasticallySuspended Load, in: ASME International Design Engineering Technical Conference. Portland, OR.

Ren, L., Jones, R.K., Howard, D., 2005. Dynamic analysis of load carriage biomechanics during level walking. J. Biomech. 38, 853-863.

Rome, L.C., Flynn, L., Goldman, E.M., Yoo, T.D., 2005. Generating electricity while walking with loads. Science (80-. ). 309, 1725-1728.

Rome, L.C., Flynn, L., Yoo, T.D., 2006. Biomechanics: Rubber bands reduce the cost of carrying loads. Nature 444, 1023-1024.

Sharp, R.S., Crolla, D.A., 1987. Road Vehicle Suspension System Design - a review. Veh. Syst. Dyn. 16, 167-192. doi:10.1080/00423118708968877

Shen, Z., Seipel, J., 2015a. The Leg Stiffnesses Animals use may Improve the Stability of Locomotion. J. Theor. Biol. 377, 66-74. doi:10.1016/j.jtbi.2015.04.010

Shen, Z., Seipel, J., 2015b. Animals prefer leg stiffness values that may reduce the energetic cost of locomotion. J. Theor. Biol. 364, 433-8. doi:10.1016/j.jtbi.2014.09.008

Shen, Z., Seipel, J., 2012. A fundamental mechanism of legged locomotion with hip torque and leg damping. Bioinspir. Biomim. 7, 46010.

Silder, A., Besier, T., Delp, S.L., 2015. Running with a load increases leg stiffness. J. Biomech. 48, 1003-1008. doi:10.1016/j.jbiomech.2015.01.051

Xingye, D., Ackerman, J., Seipel, J., 2013. Energetic and Dynamic Analysis of Multi-Frequency Legged Robot Locomotion with an Elastically-Suspended Load. ASME J. Comput. Nonlinear Dyn. 9. doi:10.1115/1.4024778

Zhang, L.Q., Xu, D., Makhsous, M., Lin, F., 2000. Stiffness and viscous damping of the human leg, in: 24th Annual Meeting of the American Society of Biomechanics. Chicago, IL, USA. 


\section{Figures, Tables, and Captions}

Figure 1 - Various load suspensions have been studied in prior work, including a compliant pole suspension (Castillo et al., 2014; Kram, 1991; Potwar et al., 2014) (a, image from Wikipedia commons), the Steadicam ${ }^{\circledR}$ camera suspension system (Ackerman and Seipel, 2015; Jurgens, 1978) (b, image reproduced from Ackerman and Seipel, 2015), a backpack suspension (Foissac et al., 2009; Rome et al., 2006, 2005) (c, image adapted from Foissac et al. 2009), the modern horse jockey riding style (Pfau et al., 2009) (d, image reproduced from Pfau et al 2009), and a robot suspension (Ackerman and Seipel, 2013) (e, image reproduced from Ackerman and Seipel, 2013).

Figure 2 - a) A two degree-of-freedom vertically-constrained spring-mass-damper (Coupled SMD) model can be used to simulate the dynamics of the body mass and the load mass in the vertical direction as a coupled system during human walking or running. b) The SLIP-Load model of running with a vertically-constrained load suspension represents the coupled interaction between the body and the load during human running. The load suspension is assumed to be vertically constrained because it is typically intended to reduce the effective gravitational load on the body.

Figure 3 - The four eigenvalues branches of the Coupled SMD and SLIP-Load model are shown with a suspended load (solid lines) and an effectively rigid load attachment (dashed lines) for increasing load mass ratio $\mathrm{M} / \mathrm{m}$ (a, suspended load: $\omega_{\mathrm{n}}=0.5 \mathrm{~Hz}, \xi=0.1 ; \mathrm{b}$, rigidly attached load: $\left.\omega_{\mathrm{n}}=10 \mathrm{~Hz}, \xi=0.5\right)$, suspension natural frequency $\omega_{\mathrm{n}}(\mathrm{c}$, suspended load: $\mathrm{M}=25 \mathrm{~kg}, \xi=0.1 ; \mathrm{d}$, rigidly attached load: $\mathrm{M}=25 \mathrm{~kg}, \omega_{\mathrm{n}}=10 \mathrm{~Hz}, \xi=0.5$ ), and suspension damping ratio $\xi$ (e, suspended load: $M=25 \mathrm{~kg}, \omega_{\mathrm{n}}=0.5 \mathrm{~Hz}$; f, rigidly attached load: $\mathrm{M}=25 \mathrm{~kg}, \omega_{\mathrm{n}}=10 \mathrm{~Hz}, \xi=0.5$ ) values. The other model parameters are shown in (Table 1). In all cases, the topmost solid black eigenvalue branches and bottommost dashed black eigenvalue are complex conjugate pairs which show that a suspended load is significantly less stable than a rigidly-attached load. The blue eigenvalue branches primarily correspond to the body mass state variables and show that the stability of the body mass increases with a suspended load compared to a rigidly attached load. The red eigenvalue branches do not show significant differences. 
Figure 4 - The Coupled SMD and SLIP-Load model show the same basic dynamic behavior with a suspended load and a rigidly attached load. The motion of the suspended load is highly decoupled from the motion of the body mass, while the motion of the rigidly attached load is tightly coupled to the motion of the body mass.

Figure 5 - This plot shows the proportion of perturbation remaining for the Coupled SMD model over multiple cycles for each state variable (columns, $\mathbf{y}, \dot{\mathbf{y}}, \mathbf{Y}, \dot{\mathbf{Y}}$ ) after individual state variables are perturbed (rows, $\boldsymbol{\delta} \mathbf{y}, \boldsymbol{\delta} \dot{\mathbf{y}}, \boldsymbol{\delta} \mathbf{Y}, \boldsymbol{\delta} \dot{\mathbf{Y}}$ ) with a representative suspended load (solid line, $\omega_{\mathrm{n}}=0.5 \mathrm{~Hz}, \xi=0.1, \mathrm{M}=25 \mathrm{~kg}$ ) and rigidly attached load (dashed line, $\omega_{\mathrm{n}}=10 \mathrm{~Hz}, \xi=0.5, \mathrm{M}=$ $25 \mathrm{~kg})$. The perturbation responses corresponding to the body mass $(\mathbf{y}, \dot{\mathbf{y}} ; \boldsymbol{\delta} \mathbf{y}, \boldsymbol{\delta} \dot{\mathbf{y}})$ show that the body mass degrees of freedom return to steady state faster with a suspended load than with a rigidly attached load. The differences between the convergence rates are relatively small because the magnitudes of the eigenvalues are relatively small (very stable) for the linear Coupled SMD model, but the stability differences can still be readily observed. The other perturbation responses show that the load mass degrees of freedom take significantly longer to return to steady state with a suspended load versus a rigidly attached load. The oscillatory behavior seen in many of the perturbation responses are a result of the differences between the natural frequency of the highly-compliant load suspension $\left(\omega_{\mathrm{n}}=0.5 \mathrm{~Hz}\right)$ and the higher overall system forcing frequency $(\omega=3 \mathrm{~Hz})$, which governs the cycle period.

Figure 6 - This plot shows the proportion of perturbation remaining for the SLIP-Load model over multiple cycles for each state variable (columns, $\mathbf{v}_{\mathbf{x}}, \mathbf{v}_{\mathbf{y}}, \mathbf{Y}, \dot{\mathbf{Y}}$ ) after individual state variables are perturbed (rows, $\delta \mathbf{v}_{\mathbf{x}}, \delta v_{\boldsymbol{y}}, \boldsymbol{\delta} \mathbf{Y}, \boldsymbol{\delta} \dot{\mathbf{Y}}$ ) with a representative suspended load (solid line, $\omega \mathrm{n}=0.5 \mathrm{~Hz}, \xi=0.1, \mathrm{M}=25 \mathrm{~kg}$ ) and rigidly attached load (dashed line, $\omega_{\mathrm{n}}=10 \mathrm{~Hz}, \xi=0.5$, $\mathbf{M}=25 \mathrm{~kg})$. The perturbation responses corresponding to the body mass state variables $\left(\mathbf{v}_{\mathbf{x}}\right.$, $\mathbf{v}_{\mathbf{y}} ; \boldsymbol{\delta} \mathbf{v}_{\mathbf{x}}, \boldsymbol{\delta} \mathbf{v}_{\mathbf{y}}$ ) and other perturbation responses show that the body mass state variable return to steady state faster with a suspended load than with rigidly attached load. The convergence rates are much slower for the SLIP-Load model than the Coupled SMD model because the magnitudes of the eigenvalues are larger for the SLIP-Load model. The perturbation responses closely associated with the load mass state variables $(\boldsymbol{Y}, \dot{\boldsymbol{Y}} ; \boldsymbol{\delta} \mathbf{Y}, \boldsymbol{\delta} \dot{\mathbf{Y}})$ show that the load mass degrees of freedom take significantly longer to return to steady state with a suspended load versus a rigidly attached load. The oscillatory behavior seen in many of the perturbation responses are a result of 
the differences between the natural frequency of the highly-compliant load suspension $\left(\omega_{\mathrm{n}}=0.5\right.$ $\mathrm{Hz}$ ) and the faster locomotion cycle period defined by one touchdown to the next touchdown. 
Table 1 - The parameters used to approximate human running in this study were based on prior work and chosen such that the model was stable over the parameter range with fore-aft dynamics that resemble human running. Many of the effective human parameters may change in practice while running with a load mass, such as the virtual leg stiffness, damping, landing angle, and torque. However, since it is currently not known how these effective parameters may change while running with increasing load mass, they are fixed for the purposes of this study. We varied the load mass up to $35 \mathrm{~kg}$, or $50 \%$ of the assumed $70 \mathrm{~kg}$ body mass. It would be difficult for the average person to run at $3 \mathrm{~m} / \mathrm{s}$ with a $35 \mathrm{~kg}$ load, but this situation is conceivable for soldiers (Epstein et al., 1987; Knapik et al., 2004).

\begin{tabular}{|c|c|c|c|}
\hline Parameter & Name & & Value \\
\hline \multicolumn{4}{|c|}{ Shared Model Parameters } \\
\hline $\mathrm{M}$ & Load Mass & & $1-35 \mathrm{~kg}$ \\
\hline$\omega_{\mathrm{n}}$ & Damped Natural Frequency & & $\begin{array}{c}0.1-1.5 \mathrm{~Hz} \text { (suspended) } \\
10 \mathrm{~Hz} \text { (rigid) }\end{array}$ \\
\hline$\zeta$ & Damping Ratio & & $\begin{array}{c}0.1-0.5 \text { (suspended) } \\
0.5 \text { (rigid) }\end{array}$ \\
\hline $\mathrm{k}$ & Virtual Leg Stiffness & & $\begin{array}{c}k=\frac{(\mathrm{m}+\mathrm{M}) \mathrm{gK}_{\mathrm{rel}}}{l_{o}} \text { (Blickhan and } \\
\text { Full, 1993; Shen and Seipel, } \\
\text { 2015b; Silder et al., 2015) }\end{array}$ \\
\hline $\mathrm{K}_{\text {rel }}$ & $\begin{array}{c}\text { Dimensionless Virtual Leg } \\
\text { Stiffness }\end{array}$ & & $\begin{array}{l}20 \text { (Blickhan and Full, 1993; } \\
\text { Shen and Seipel, 2015b) }\end{array}$ \\
\hline $1_{0}$ & $\begin{array}{l}\text { Virtual Leg Length from the } \\
\text { Human Body Center of Mass to } \\
\text { the Foot Center of Pressure }\end{array}$ & & $1 \mathrm{~m}$ (Geyer et al., 2006) \\
\hline $\mathrm{c}$ & Virtual Leg Damping & & $\begin{array}{l}1200 \mathrm{Ns} / \mathrm{m} \text {, increased from } 950 \\
\text { Ns/m (Zhang et al., 2000) for } \\
\text { improved system stability with } \\
\text { large load mass variations }\end{array}$ \\
\hline $\mathrm{m}$ & Human Mass & & $70 \mathrm{~kg}$ \\
\hline \multicolumn{4}{|c|}{ Coupled SMD Model-Specific Parameters } \\
\hline$\omega$ & Forcing frequency & & $3 \mathrm{~Hz}$ \\
\hline A & Forcing amplitude & & $0.0254 \mathrm{~m}$ \\
\hline \multicolumn{4}{|c|}{ SLIP-Load Model-Specific Parameters } \\
\hline$\beta$ & Virtual Leg Landing Angle beta & & $65^{\circ}$ (Shen and Seipel, 2012) \\
\hline$\tau$ & Virtual Leg Torque & & Variable \\
\hline $\mathrm{v}_{\mathrm{t}}$ & Target Running Speed & & $3 \mathrm{~m} / \mathrm{s}$ \\
\hline $\mathrm{g}$ & Gravity & & $9.81 \mathrm{~m} / \mathrm{s}^{2}$ \\
\hline
\end{tabular}


Table 2 - The eigenvectors associated with each eigenvalue for a representative case $(M=$ $25 \mathrm{~kg}$ ) provide a means of quantifying the coupled interactions between the state variables of the Coupled SMD and SLIP-Load model. The bold values indicate eigenvector components with a magnitude above 0.05 to highlight the most significant components. Both models show the same overall behavior for the suspended load and rigid load, though the eigenvalues and eigenvector components vary. For the suspended load, the eigenvectors for both models show that the body mass state variables $\left(\boldsymbol{v}_{\mathbf{x}}\right.$ and $\left.\boldsymbol{v}_{\mathbf{y}}\right)$ and the load mass state variables $\left(\boldsymbol{Y}_{\mathbf{0}}\right.$ and $\left.\dot{Y}_{\mathbf{0}}\right)$ are effectively decoupled from one another. There is not a significant dynamic interaction between the body and the load because the highly-compliant and lightly-damped suspension effectively decouples the motion of the load from that of the body. The eigenvectors for the rigidly attached load mass show a significant interaction between the stability of the body mass state variables $\boldsymbol{v}_{\mathbf{x}}$ and $\boldsymbol{v}_{\mathbf{y}}$ and the load velocity $\dot{\boldsymbol{Y}}_{\mathbf{0}}$. This coupled interaction between the load mass and the body mass is caused by the very stiff and highly-damped load attachment and may explain why the eigenvalues corresponding to the body mass are larger for the rigid load than for the suspended load.

\section{Coupled SMD Model}

Suspended Load $\quad M=25 \mathrm{~kg} \quad \zeta=0.1 \quad \omega_{\mathrm{n}}=0.5 \mathrm{~Hz}$

\begin{tabular}{|c|c|c|c|c|}
\hline Eigenvalue & $\mathbf{0 . 0 5 5}$ & $\mathbf{0 . 0 5 5}$ & $\mathbf{0 . 9 0 1}$ & $\mathbf{0 . 9 0 1}$ \\
\hline State Parameter & \multicolumn{4}{|c|}{ Eigenvector } \\
\hline$y$ & $\mathbf{0 . 0 6 1}$ & $\mathbf{0 . 0 6 1}$ & 0.004 & 0.004 \\
\hline$\dot{y}$ & $\mathbf{0 . 9 9 7}$ & $\mathbf{0 . 9 9 7}$ & 0.013 & 0.013 \\
\hline$Y$ & 0.002 & 0.002 & $\mathbf{0 . 3 0 4}$ & $\mathbf{0 . 3 0 4}$ \\
\hline$\dot{Y}$ & 0.038 & 0.038 & $\mathbf{0 . 9 5 3}$ & $\mathbf{0 . 9 5 3}$ \\
\hline
\end{tabular}

Rigid Load $\quad \mathrm{M}=25 \mathrm{~kg} \quad \zeta=0.5 \quad \omega_{\mathrm{n}}=10 \mathrm{~Hz}$

\begin{tabular}{|c|c|c|c|c|}
\hline Eigenvalue & $\mathbf{0 . 1 2 5}$ & $\mathbf{0 . 1 2 5}$ & 4.4E-06 & $\mathbf{2 . 0 E - 0 7}$ \\
\hline State Parameter & \multicolumn{4}{|c|}{ Eigenvector } \\
\hline$y$ & $\mathbf{0 . 0 5 0}$ & $\mathbf{0 . 0 5 0}$ & 0.016 & 0.026 \\
\hline$\dot{y}$ & $\mathbf{0 . 6 9 5}$ & $\mathbf{0 . 6 9 5}$ & $\mathbf{0 . 1 4 5}$ & $\mathbf{0 . 6 4 3}$ \\
\hline$Y$ & $\mathbf{0 . 0 5 1}$ & $\mathbf{0 . 0 5 1}$ & 0.034 & $\mathbf{0 . 0 6 0}$ \\
\hline$\dot{Y}$ & $\mathbf{0 . 7 1 6}$ & $\mathbf{0 . 7 1 6}$ & $\mathbf{0 . 9 8 9}$ & $\mathbf{0 . 7 6 3}$ \\
\hline
\end{tabular}




\section{SLIP-Load Model}

Suspended Load $\quad M=25 \mathrm{~kg} \quad \zeta=0.1 \quad \omega_{\mathrm{n}}=0.5 \mathrm{~Hz}$

\begin{tabular}{|c|c|c|c|c|}
\hline Eigenvalue & $\mathbf{0 . 7 7 9}$ & $\mathbf{0 . 0 6 4}$ & $\mathbf{0 . 9 1 5}$ & $\mathbf{0 . 9 1 5}$ \\
\hline State Parameter & \multicolumn{5}{|c|}{ Eigenvector } \\
\hline$v_{\mathrm{x}}$ & $\mathbf{0 . 9 8 8}$ & $\mathbf{0 . 9 5 9}$ & 0.036 & 0.036 \\
\hline$v_{\mathrm{y}}$ & $\mathbf{0 . 1 5 4}$ & $\mathbf{0 . 2 7 9}$ & 0.013 & 0.013 \\
\hline$Y_{0}$ & 0.001 & 0.001 & $\mathbf{0 . 3 0 5}$ & $\mathbf{0 . 3 0 5}$ \\
\hline$\dot{Y}_{0}$ & 0.009 & 0.047 & $\mathbf{0 . 9 5 2}$ & $\mathbf{0 . 9 5 2}$ \\
\hline
\end{tabular}

Rigid Load $\quad \mathrm{M}=25 \mathrm{~kg} \quad \zeta=0.5 \quad \omega_{\mathrm{n}}=10 \mathrm{~Hz}$

\begin{tabular}{|c|c|c|c|c|}
\hline Eigenvalue & $\mathbf{0 . 9 3 6}$ & $\mathbf{0 . 0 6 8}$ & 3.3E-04 & 4.1E-08 \\
\hline State Parameter & \multicolumn{4}{|c|}{ Eigenvector } \\
\hline$v_{\mathrm{x}}$ & $\mathbf{0 . 9 7 7}$ & $\mathbf{0 . 5 6 7}$ & $\mathbf{0 . 1 1 1}$ & $\mathbf{0 . 4 3 3}$ \\
\hline$v_{\mathrm{y}}$ & $\mathbf{0 . 1 4 1}$ & $\mathbf{0 . 1 9 6}$ & $\mathbf{0 . 1 0 4}$ & $\mathbf{0 . 0 7 7}$ \\
\hline$Y_{0}$ & $1.1 \mathrm{E}-06$ & $1.5 \mathrm{E}-06$ & $6.1 \mathrm{E}-05$ & 0.043 \\
\hline$\dot{Y}_{0}$ & $\mathbf{0 . 1 6 0}$ & $\mathbf{0 . 8 0 0}$ & $\mathbf{0 . 9 8 8}$ & $\mathbf{0 . 8 9 7}$ \\
\hline
\end{tabular}


a)

Compliant Bamboo Carrying Poles

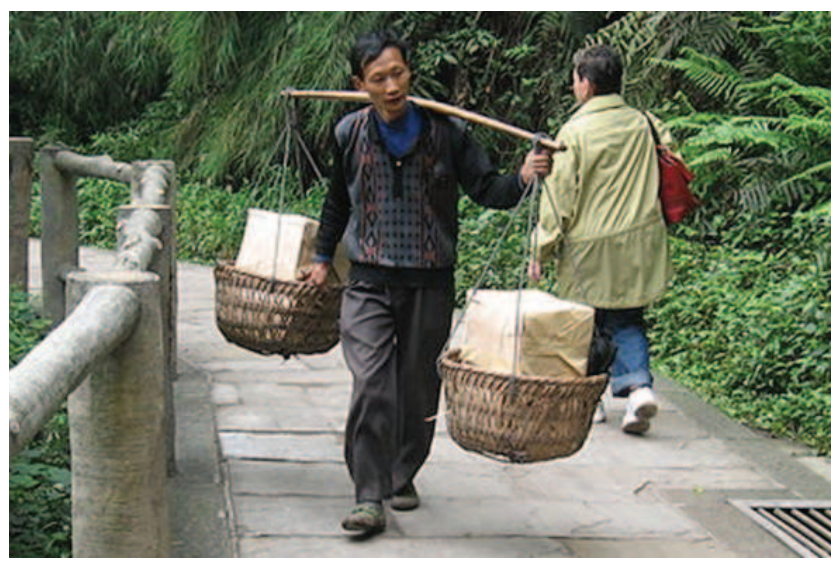

b)

Steadicam ${ }^{\circledR}$ Camera Suspension

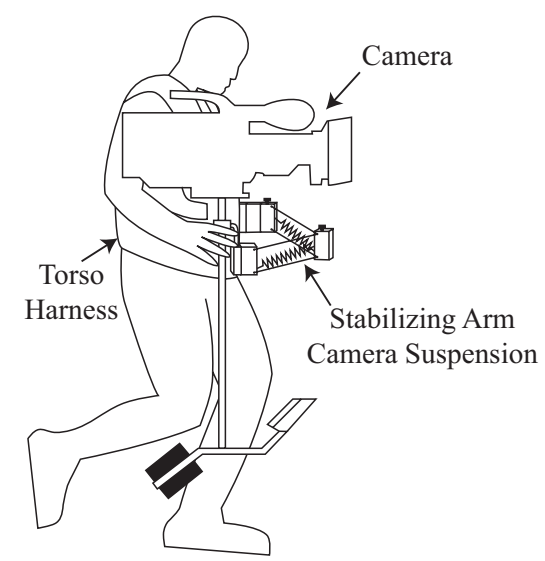

c)

Backpack Suspension

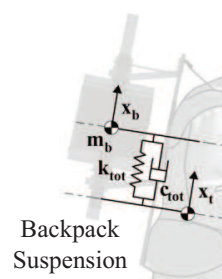

e)

d)

Modern 'Compliant' Leg Jockey Riding Style

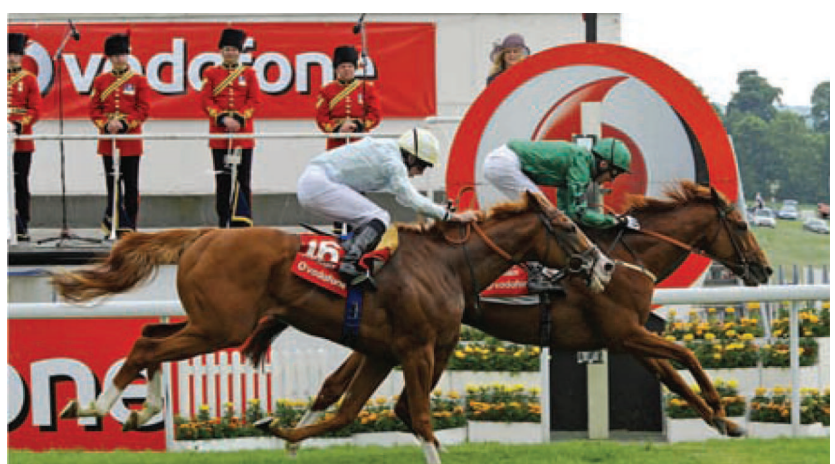

Legged Robot Suspension

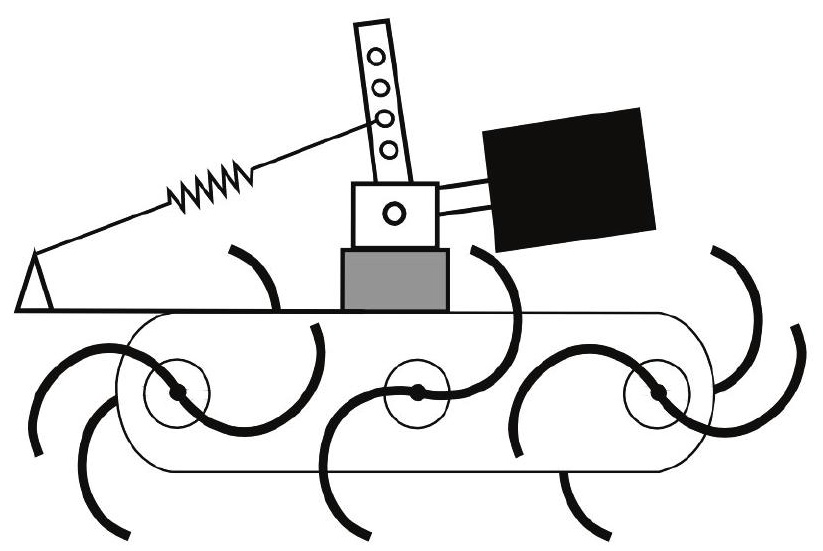


a) Coupled SMD Model
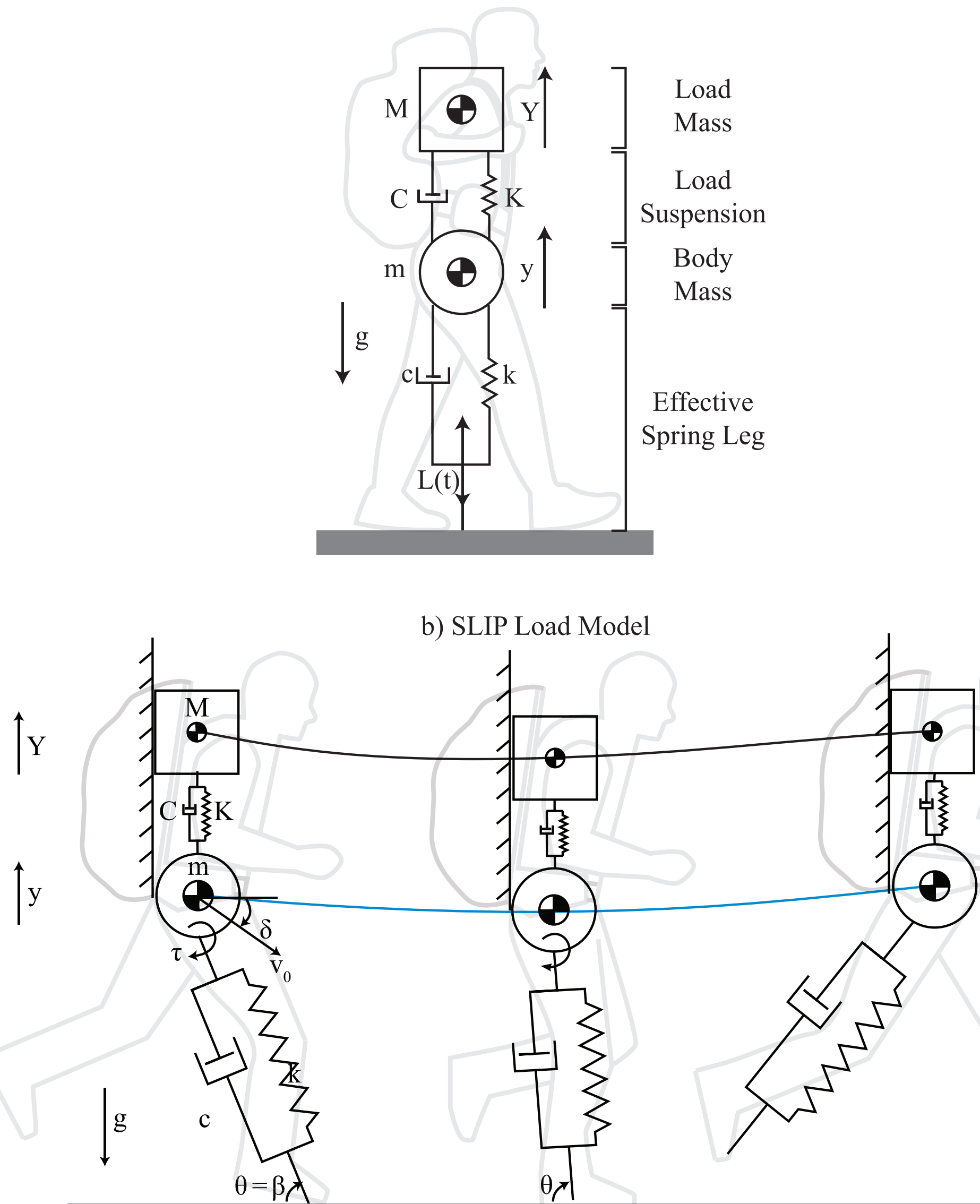
Figure 3

Coupled SMD Model

a)

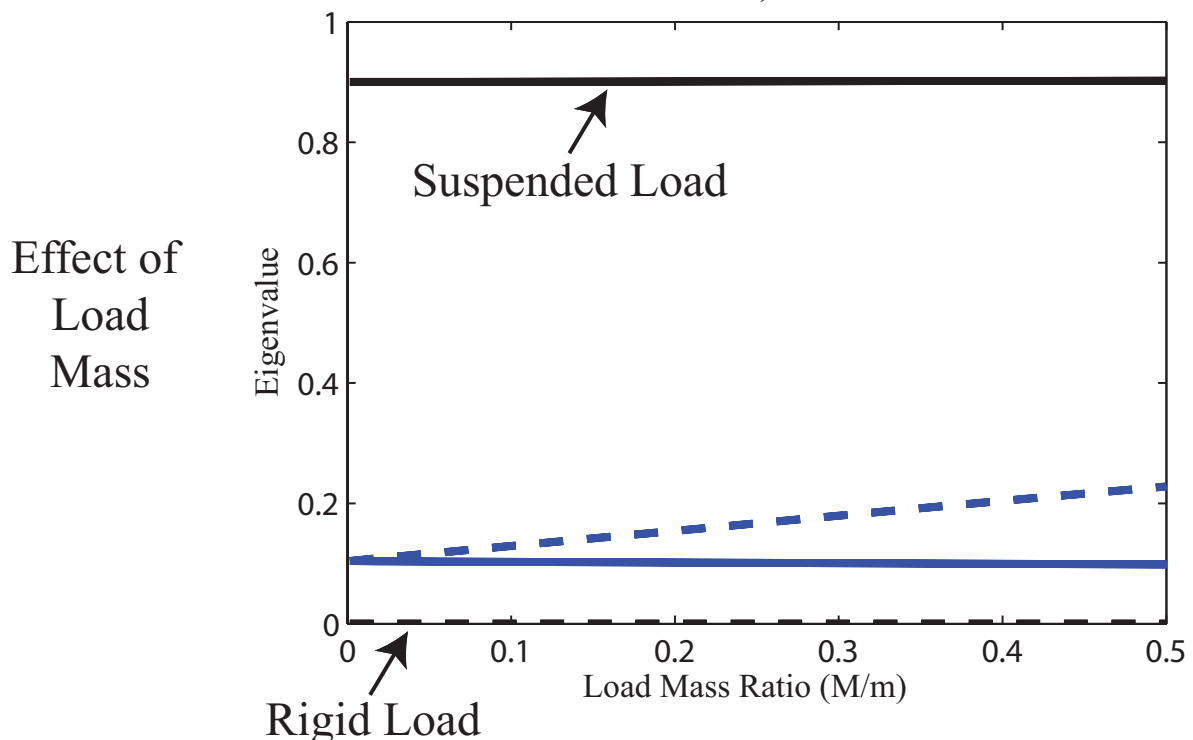

c)

Effect of Damping Ratio

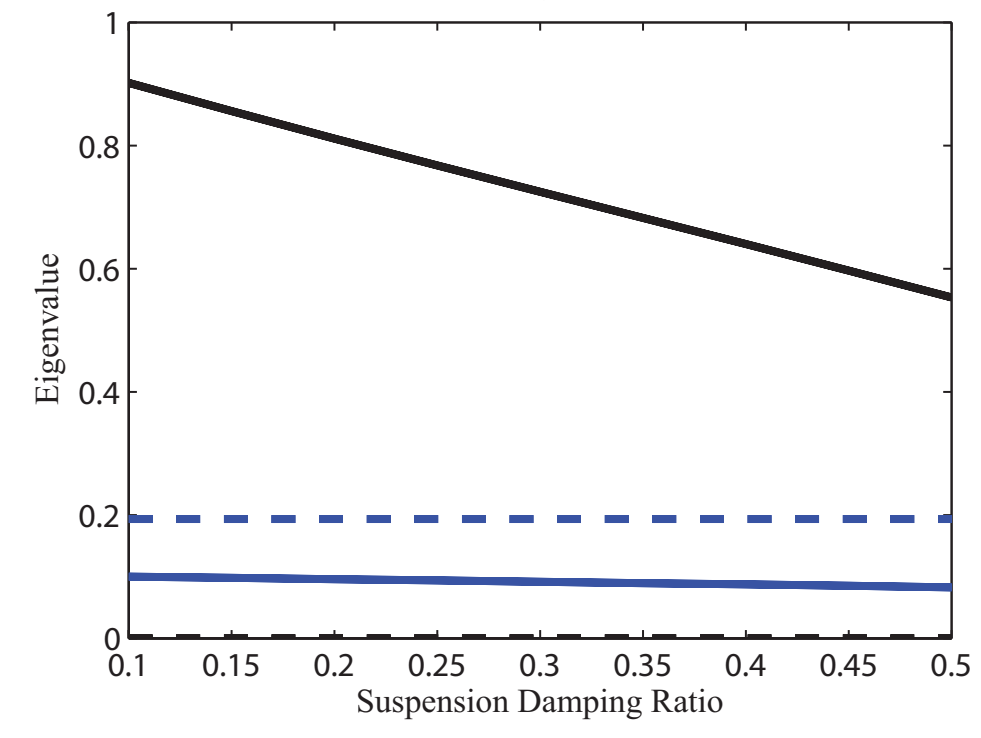

e)

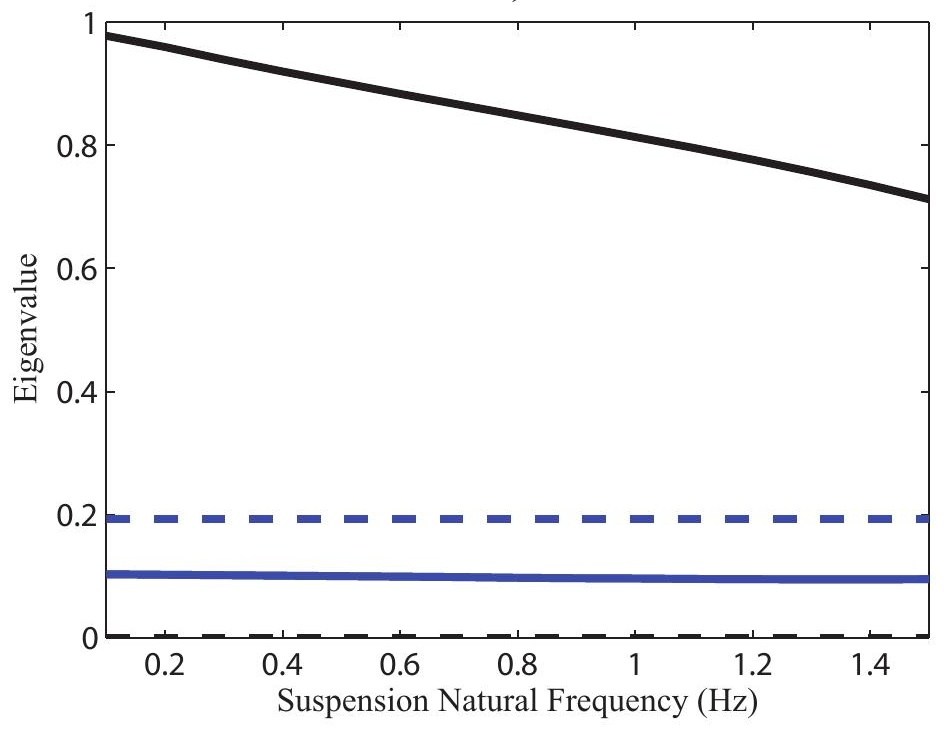

SLIP-Load Model

b)

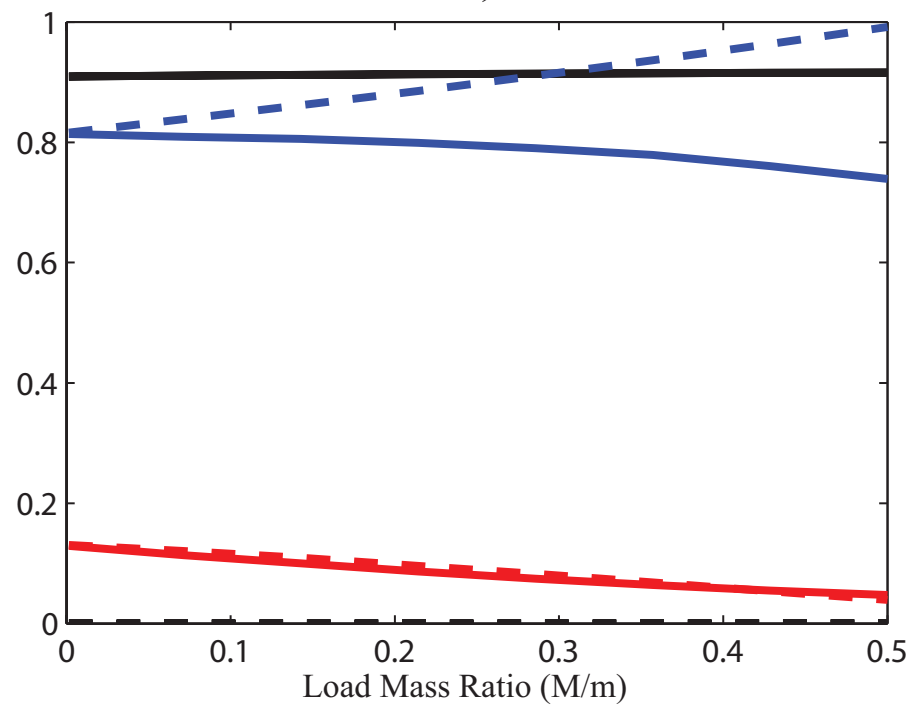

d)

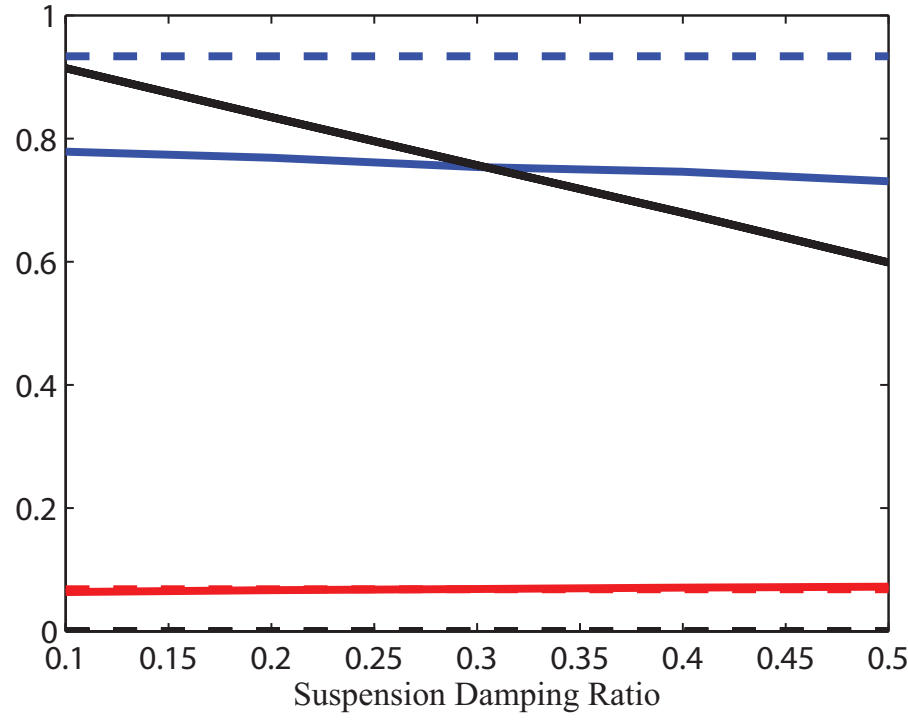

f)

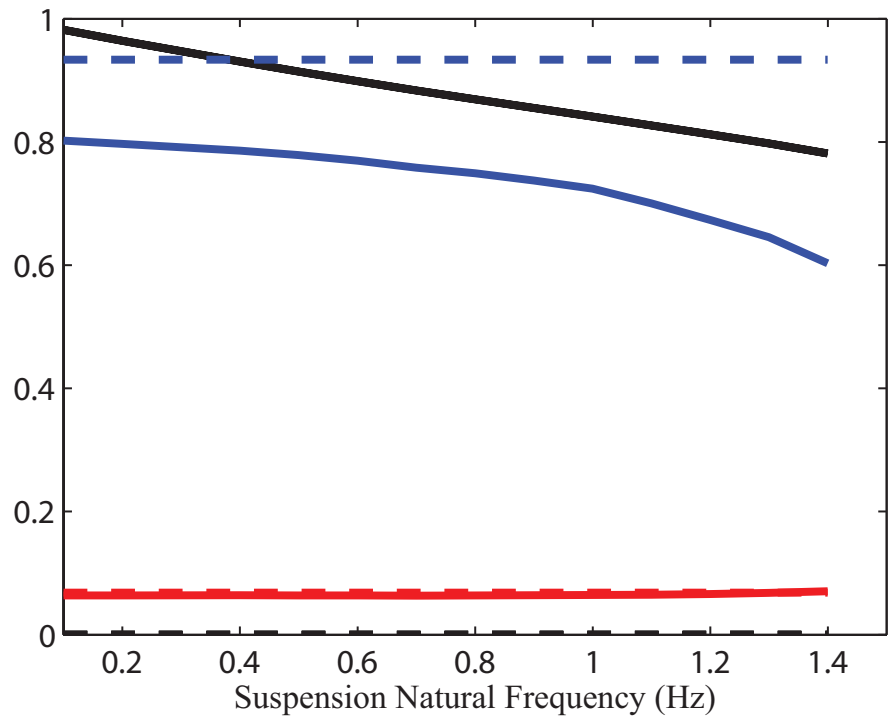


Figure 4
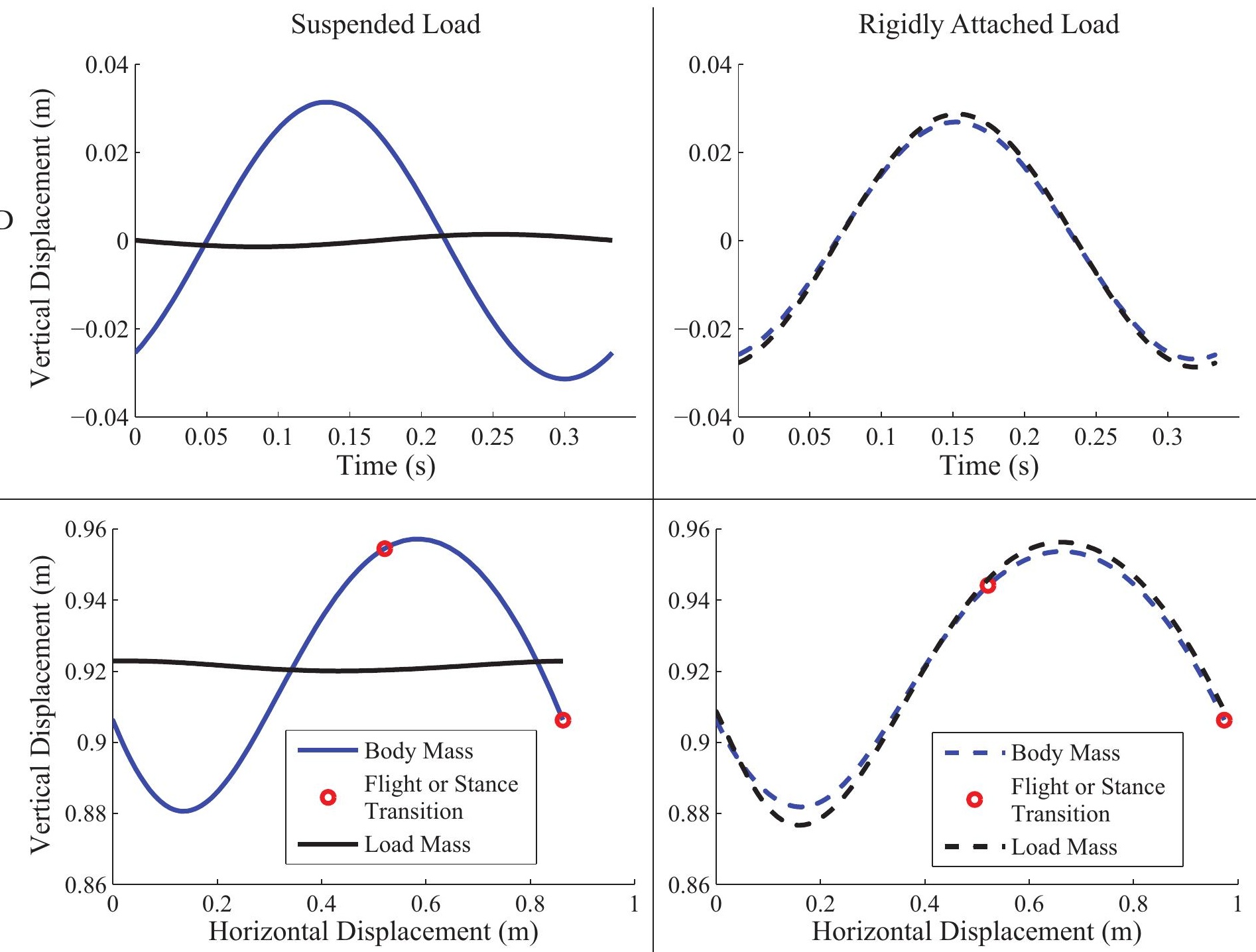

SLIP-Load

Model 
Coupled SMD Model

State Variable Response

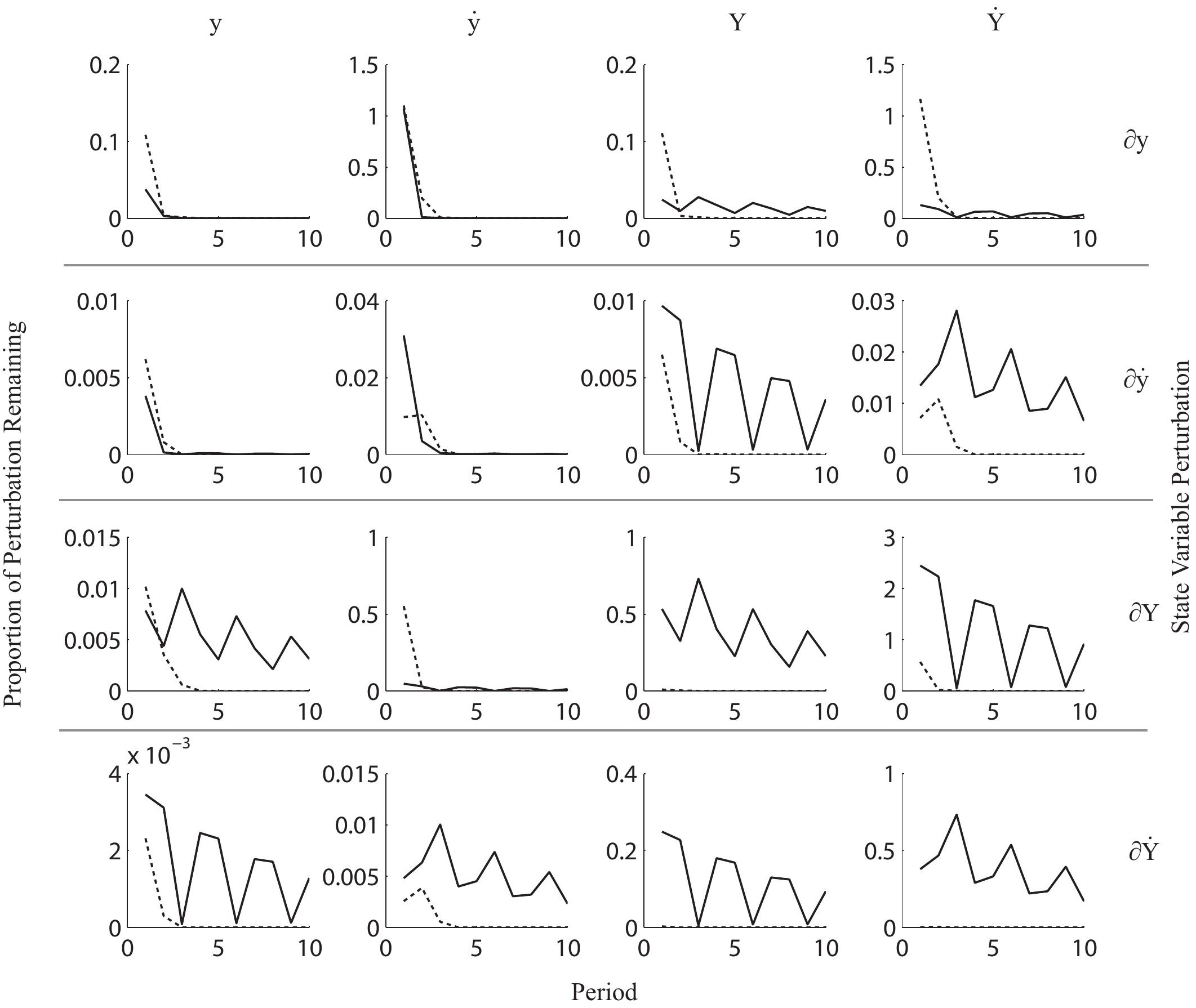


SLIP-Load

State Variable Response
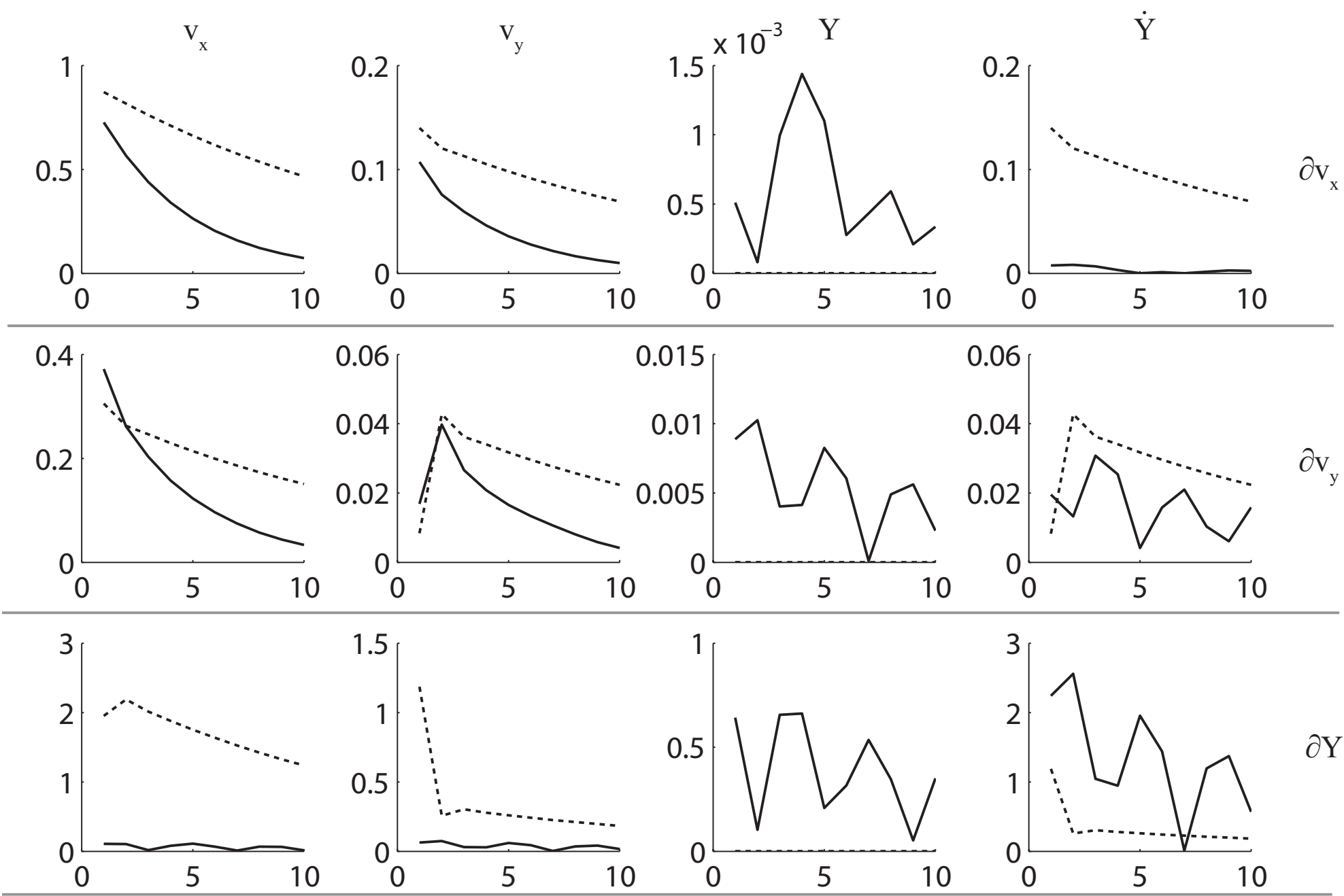

0.015

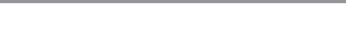

0.06

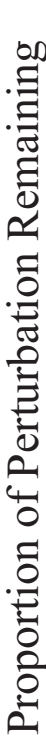
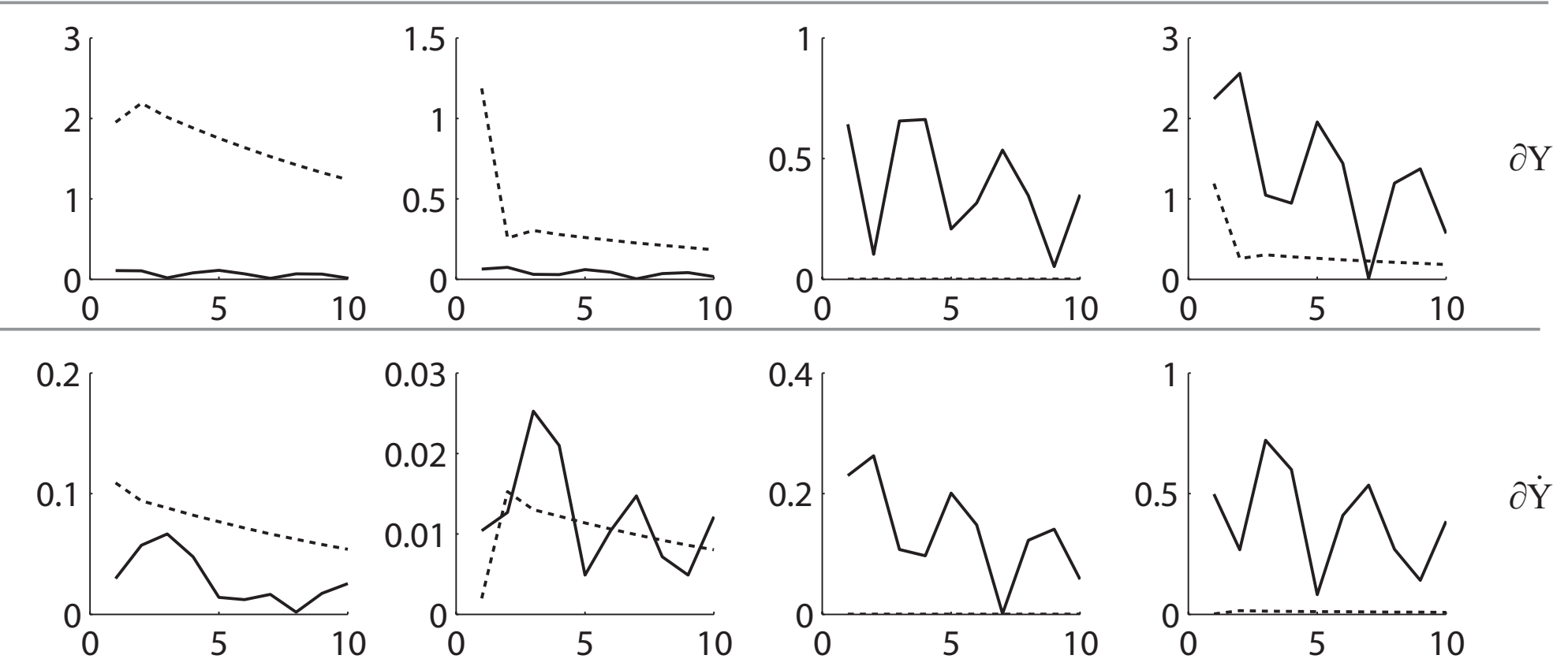

Period 